\title{
Modeling the ecological impact of heavy metals on aquatic ecosystems: a framework for the development of an ecological model
}

\author{
Mengchang $\mathrm{He}^{\mathrm{a}, \mathrm{b}, *}$, Zijian Wang ${ }^{\mathrm{a}}$, Hongxiao Tang ${ }^{\mathrm{a}}$ \\ ${ }^{\text {a }}$ State Key Laboratory of Environmental Aquatic Chemistry, Research Center for Eco-Environmental Sciences, \\ Chinese Academy of Sciences, P.O. Box 2871, Beijing 100085, PR China \\ ${ }^{\mathrm{b}}$ Institute of Environmental Science, Beijing Normal University, Beijing 100875, PR China
}

Received 17 September 1999; accepted 28 June 2000

\begin{abstract}
In this paper, an ecological model is proposed to predict the effects of heavy metals on aquatic ecosystems. The bioavailable concentration of metals and a concept of toxicity strength (TS) are combined. The integrated ecological model relates the transport, distribution and speciation of heavy metals and their toxicity, and the effect of environmental variability on metal toxicity. It also emphasizes the link between physical and chemical processes of heavy metals in rivers and ecological effects. Based on the data obtained from research in the CERP project (Co-operative Ecological Research Project), the ecological impact of heavy metals on the aquatic ecosystem of the Le An River (polluted by heavy metals from a copper mine) was predicted. The results show that the estimated values of toxicity strength for surface water are in agreement with the percentage inhibition for the test organism $(P$. phosphoreum) and that the predicted ecological effect of polluted sediment is consistent with natural variability in aquatic ecosystems. (c) 2001 Elsevier Science B.V. All rights reserved.
\end{abstract}

Keywords: River water; Sediment; Heavy metals; Toxicity strength; Ecological model

\section{Introduction}

Heavy metal pollution in rivers and its impact on aquatic ecosystems is a dynamic process. Assessing the impacts on whole ecosystems and con-

\footnotetext{
* Corresponding author. Tel.: +86-10-62207808; fax: +8610-62200397.

E-mail address: hemc@263.net (M. He).
}

structing an ecological model are multi-disciplinary scientific problems and pose a major challenge to the understanding of heavy metal pollution.

The transport and transformation of heavy metals in rivers are well investigated in field experiments and models. Still little is known about the link between these processes and the whole ecosystem. Hakanson (1984) established a conceptual model on the relationship between dose, 
recipient sensitivity of heavy metals and potential effect. Usually principal component and multiple regression analyses are used to identify the ecological effects of pollutants on aquatic ecosystems (Mulliss et al., 1996; Adami et al., 1997). Ulbrich et al. (1997) developed a conceptual model linking processes of sediment transport and biodegradation in order to predict the ecological impact of contaminated river sediments on wetlands. Recent studies have shown that porewater concentrations are useful for predicting the bioavailability of contaminants to benthic organisms (Ankley et al., 1996). However, owing to the complexity of ecosystems and environmental variability, it is very difficult to establish a quantitative relationship between heavy metals and ecological effects in aquatic ecosystems.

China is rich in non-ferrous metal sulfide resources. The Dexing Copper Mine is the largest open-cast copper mine in Jiangxi Province, China. Discharges from the mine flow into the Le An River and finally into the Poyang Lake, the largest fresh-water lake in China. During 1987 and 1995, the Cooperative Ecological Research Project (CERP) was launched within the international Man and Biosphere (MAB) program, supported by the Federal Ministry for Research and Technology (BMBF), Germany. The 'Ecological Effects of Heavy-metal Pollution in the Dexing Copper Mine Region' program, one of eight CERP sub-projects, was carried out to assess the impact of the mining operation (Tang et al., 1994; Muller and Tang, 1996). A previous study was concerned mainly with the distribution, transport and speciation of heavy metals, pollution assessment as well as an ecological investigation. A weathering model for pyritic minerals in the mine tailings (Dai and Wang, 1992), a speciation model for heavy metals (Lin and Li, 1994), and a model of transport and transformation of heavy metals (Lin et al., 1992) were established. No attention was paid to the prediction of the ecological effect of heavy metals on the ecosystem.

The major objective of this paper was to develop a quantitative ecological model for predicting the effect of heavy metals from the Dexing Copper Mine on aquatic ecosystems in the Le An River, China.

\section{Description of the study area}

The research area is shown in Fig. 1. The Dexing Copper Mine, located near the Gukou site in the Le An River (279 km long), is the largest open-cast copper mine in Jiangxi Province, China. The Dawu River, running through the Dexing Copper Mine, receives waste discharges from the mine and flows into the Le An River at Gukou (site A04). A small tributary, the Jishui River (J.R., $39 \mathrm{~km}$ long) is also a metal-polluted river situated beside several small sulfide mines and smelters; it runs into the Le An River at Daicun (site A07) and finally flows into Poyang Lake. Consequently, a large amount of various pollutants, mainly heavy metals, have been discharged into the Le An River causing significant ecological impacts.

\section{Framework of the integrated ecological model}

In our previous studies, the weathering model of pyritic minerals in mine tailings, the models of speciation, transport and transformation of heavy metals in Le An River were established. In this study, we try to establish an integrated ecological model to link the processes of transport and transformation to ecological effects. The framework of the integrated model (Fig. 2) includes a few sub-models as follows.

\subsection{Modeling for sulfide weathering in pyritic mine tailings}

A model for sulfide weathering in pyritic mine tailings was developed based on the sulfide weathering rate in pyritic mine tailings as well as the relationship between the accumulated amount of sulfide weathered during weathering and some factors affecting it. The relationship is mainly based on the results of simulating experiment of pyritic wastestone weathering and analysis of field samples of the acid water. The model may be used to predict the rate of sulfide weathering in pyritic mine tailings at the Dexing Copper Mine and the quality of the acid mine drainage generated by the weathering (Dai and Wang, 1992). 


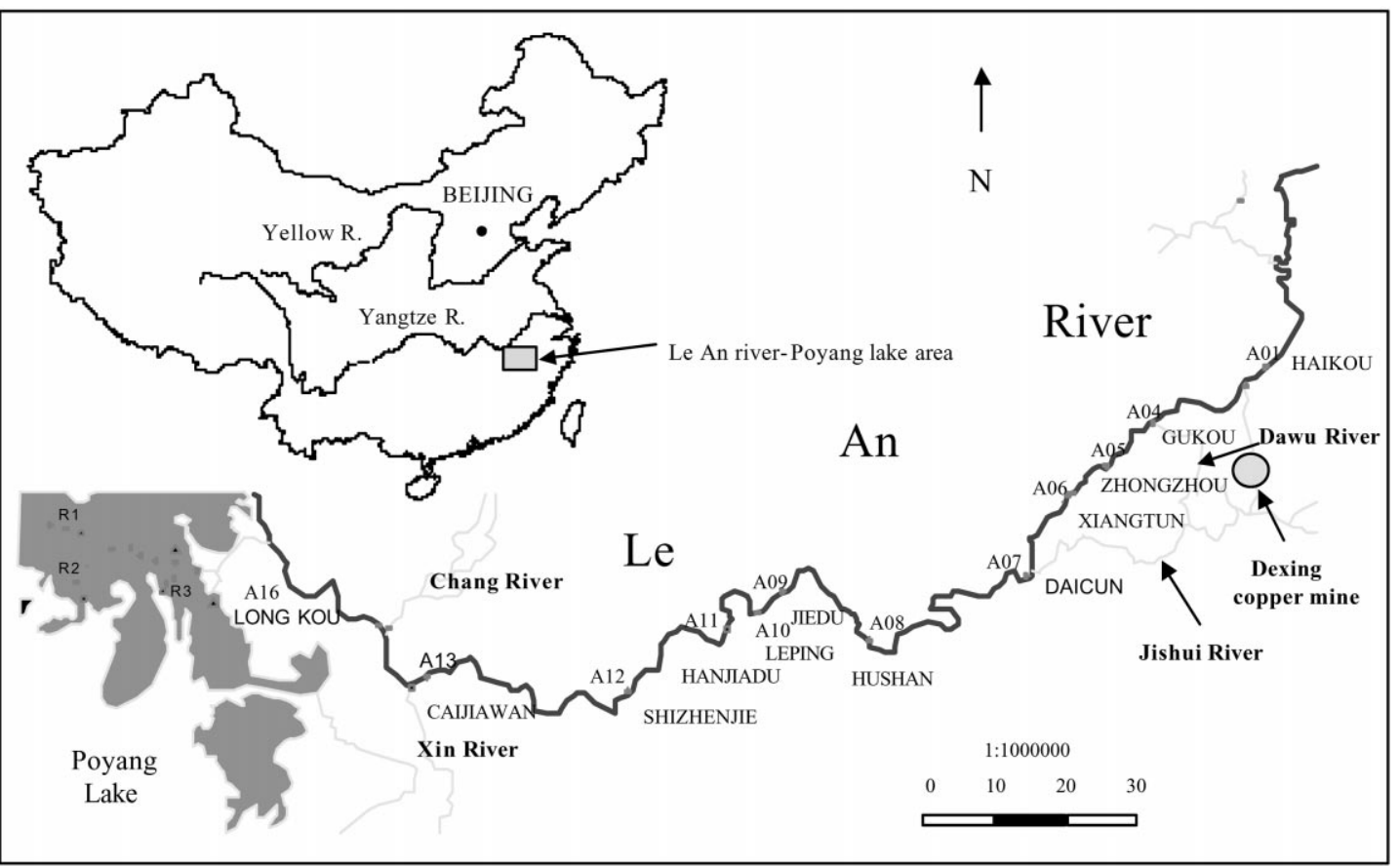

Fig. 1. Research area and sampling location.

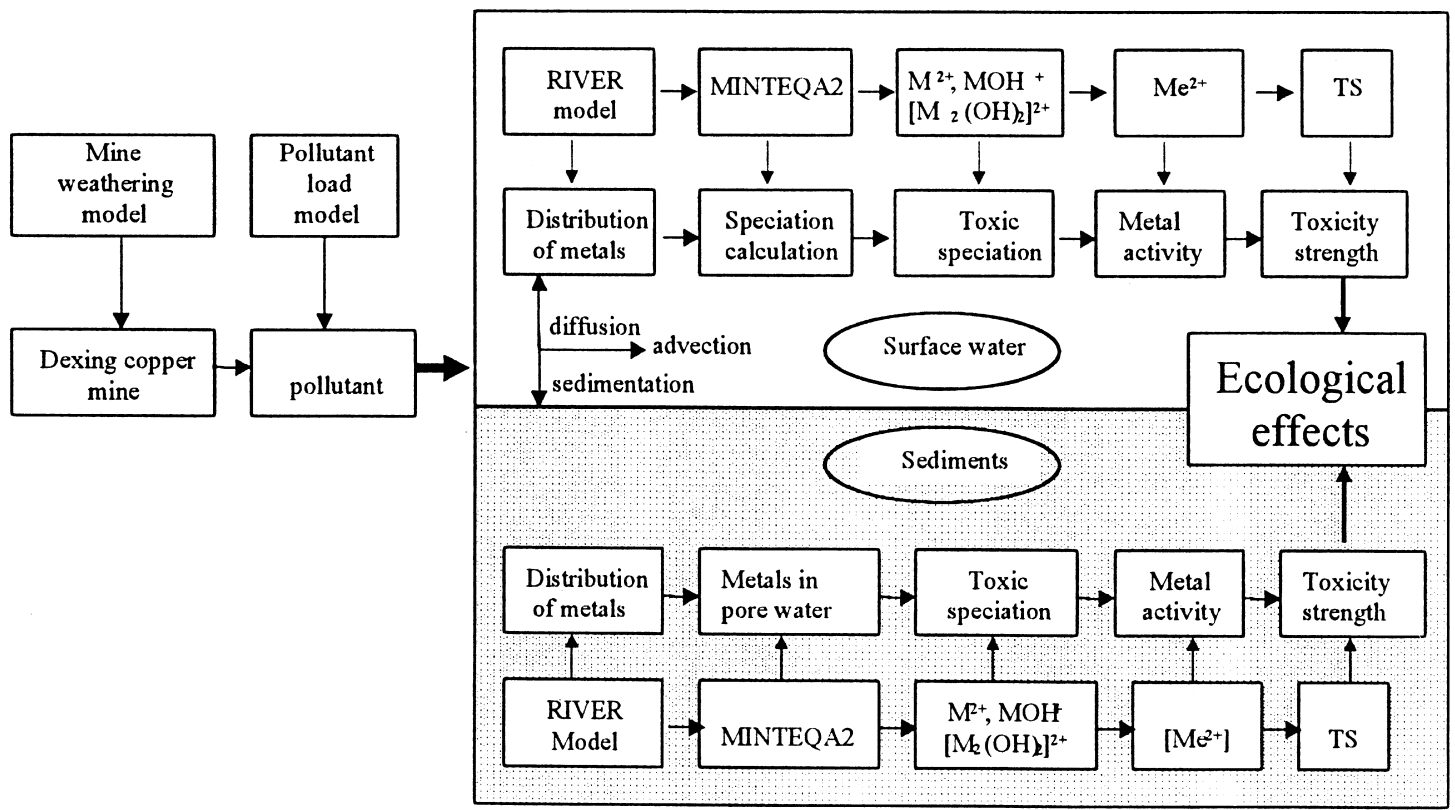

Fig. 2. Conceptual scheme of the integrated ecological model. 
The output of the model can be used to estimate the pollution loads of heavy metals to the river.

Additionally, a linear regression model was established to predict the concentrations of copper and iron in acid mine drainage based on monthly average temperature, yield of acid mine drainage, rainfall and quantity of mine tailings; and the amount of acid mine drainage was estimated $(\mathrm{Wu}$ and Xiong, 1997).

\subsection{Modeling metal transport}

In this project, the RIVER Model was used to predict the distribution of dissolved and particulate metals, and the concentration of metals in surface waters and sediment ( $\mathrm{Lin}$ and $\mathrm{Li}, 1992$ ). The output of the model provides the data for modeling the metal speciation in water and for predicting the concentration of heavy metals in interstitial water.

\subsection{Modeling metal speciation}

The chemical speciation of heavy metals in surface water was predicted using the chemical equilibrium model, MINTEQA2 program (Lin et al., 1992). The output of the model provides the data for the predictive model of ecological effects.

\subsection{Predictive model of ecological effect}

In this paper, we try to link the aforementioned sub-models, and to develop a predictive model of ecological effect of heavy metals on aquatic ecosystems.

\section{Modeling ecological effect}

\subsection{Model hypothesis}

Previous studies showed that different heavy metals and environmental variability cause different ecological effects. The effects of heavy metals on aquatic organisms are related to the metal species, speciation and environmental conditions. Thus, to predict the ecological effect of heavy metals on ecosystems, the aforementioned factors must be taken into account simultaneously.

To show the ecological effects of heavy metals on aquatic ecosystems, a concept of toxicity strength (TS) was developed. The calculation of TS is as follows: (i) bioavailability and toxicity of metals to aquatic organisms are dependent on the speciation of the metals. When calculating the TS, only the toxic speciation is considered; (ii) various metals have different toxicological effects. When calculating the TS of multiple metals, the toxicity level of different metals $\left(\mathrm{EC}_{50}\right)$ must be considered; (iii) various environmental factors influence the ecological effect of the metals. When calculating the TS of metals, these environmental factors (e.g. pH, hardness) are used to correct the TS; and (iv) since some metals have higher TS values than other metals, the toxicity strengths of the various metals are assumed to be additive.

\subsection{Metal toxic species}

The total concentrations of soluble metals in aquatic systems are the sum of the free metal ion and the metal contained in the complexes. For some trace metals, (e.g. copper) there are many different species in solution, whereas others, such as cadmium, have fewer species in natural water systems. Studies of copper toxicity to organisms have demonstrated that toxicity is not related to the total copper concentration, but rather to the concentration of free copper ions. Organically bound copper appears to be non-toxic; the most toxic inorganic forms are $\mathrm{Cu}^{2+}, \mathrm{CuOH}^{+}$and $\left[\mathrm{Cu}_{2}(\mathrm{OH})_{2}\right]^{2+}$.

In sediment systems, toxicity of heavy metals also does not correlate with sediment total metal concentration, so it is essential to identify the fraction of total metal in the sediment that is bioavailable. There is convincing evidence that sediment porewater concentrations of metals correspond well with their bioavailability (Swartz et al., 1985; Di Toro et al., 1990, 1991; Hansen et al., 1996).

Therefore, when predicting the TS of heavy metals in surface water, only the toxic metal species are included; and when predicting the TS of heavy metals in sediment, the concentrations 
of heavy metals in interstitial water are used to calculate the toxicity strength.

\subsection{Metal activity}

A substantial number of experiments using only water suggests that biological effects are often correlated to the divalent metal activity $\left\{\mathrm{M}^{2+}\right\}$. Metal activity is the molar divalent metal concentration $\left[\mathrm{M}^{2+}\right]$ corrected for the shielding effect of anions that are electrostatically attracted to the atoms in high ionic strength (e.g. concentrated) solutions (Ankley et al., 1996). In general, the free metal species, $\mathrm{M}^{2+}$, and the hydroxide complexes, $\mathrm{M}(\mathrm{OH})^{+}$and $\mathrm{M}(\mathrm{OH})_{(\mathrm{aq})}^{2}$, tend to be the most toxic, whereas complexes with carbonate, $\mathrm{M}\left(\mathrm{CO}_{3}\right)_{(\mathrm{aq})}$, exhibit minimal toxicity. The complexing speciation of natural ligands is not toxic or only slightly toxic (Allen and Hansen, 1996). Additionally, trace metal toxicity tends to decrease when the water contains higher concentrations of the 'hardness metals', namely, calcium and magnesium.

Liu (1996) studied toxicity differences using $\mathrm{Cu}^{2+}, \mathrm{CuOH}^{+}$and $\mathrm{Cu}(\mathrm{OH})_{2(\mathrm{aq})}$, and established the relationship between metal activity and toxicity for copper as follows: $\left[\mathrm{Cu}^{*}\right]=\left[\mathrm{Cu}^{2+}\right]+$ $0.75\left[\mathrm{CuOH}^{+}\right]+0.70\left[\mathrm{Cu}(\mathrm{OH})_{2(\mathrm{aq})}\right]$; where $\left[\mathrm{Cu}^{*}\right]$ was the copper activity.

\subsection{Calculation of toxicity strengths}

\subsubsection{Procedure for calculating TS for surface water}

1. Calculation for the concentration of chemical forms and metal activity: According to the modeling result of heavy metal distribution, the simulation of species distribution of the heavy metals in river water was carried out using MINTEQA 2 software. Then, the metal activity concentration $\left[\mathrm{Me}^{*}\right]$ was calculated.

2. Calculation of toxicity strength for heavy metals: The toxicity strength (TS) for a given metal in surface water is calculated as:

$\mathrm{TS}_{i}=\frac{\left[\mathrm{Me}^{*}\right]}{\mathrm{WQC}}=\frac{\left[\mathrm{Me}^{*}\right]}{\mathrm{FCV}}$

where the $\mathrm{TS}_{i}$ for a given metal, is the activity metal concentration $\left[\mathrm{Me}^{*}\right]$ divided by its corresponding water quality criteria (WQC) or final chronic value (FCV). FCVs were corrected for water hardness before the calculation of TS of surface water. Assuming an additive toxicity model, TSs for metals in surface water are summed.

\subsubsection{Procedure for calculating TS for interstitial water}

Toxicity strength for interstitial water was calculated by dividing measured dissolved metal concentrations by their respective FCVs from the WQC. Final chronic values were corrected for water hardness before the calculation of TS of interstitial water. Interstitial water TS for a given metal is calculated by:

$\mathrm{TS}=\frac{[\mathrm{Md}]}{\mathrm{FCV}}$

where $[\mathrm{Md}]$ is the dissolved interstitial water concentration of the metal. Assuming an additive toxicity model, TS values for metals in sediment are summed.

\section{Case study}

All of the data for this paper were collated from the CERP database and relevant publications (Muller and Tang, 1996; Tang et al., 1994).

\subsection{Estimation of TS for surface water in the Le An River}

Based the predicted data for the distribution, concentration and speciation of copper, lead and zinc in the water of the Le An River ( $\mathrm{Lin}$ and $\mathrm{Li}$, 1994), the TS for surface water in the Le An River was calculated.

The estimated TS levels of the dissolved metals in the surface water and relative toxicity by $P$. phosphoreum bioassay are shown in Fig. 3. The results show that the estimated TS and actual toxicity are significantly correlated. The highest TS of surface water and the highest inhibition for P. phosphoreum are at Site A07 due to high 


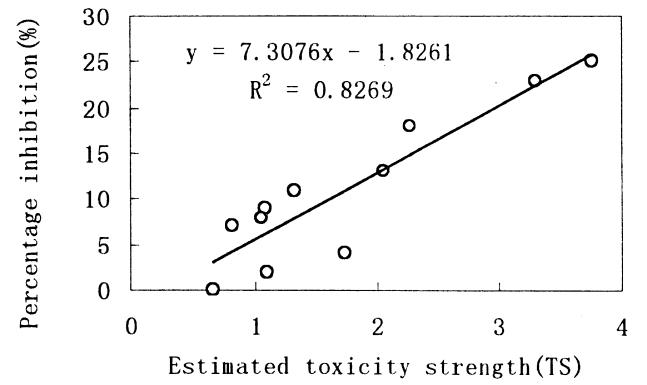

Fig. 3. Relationship between estimated toxicity strength of dissolved metals in the surface water and actual toxicity by $P$. phosphoreum bioassay.

contents of copper and zinc from the Dexing Copper Mine and the Jishui River. The TS strength of the surface water at other sites is low and so the effect on the test organism is slight.

\subsection{Estimation of TS for interstitial water in the Le An River}

According to previous studies, a high concentration of copper in the sediment of the Le An River is the main pollution problem ( $\mathrm{He}$ et al., 1997, 1998). Therefore, when calculating TS for interstitial water, only the copper concentration is considered. Based on the predicted data for the concentration of copper in the sediment of the Le An River (Lin and Li, 1994), the concentration of copper in interstitial water can be predicted according to the formula (Ge, 1997):

$C_{i}=C_{t} \times 0.00003+0.00731$

where $C_{i}$ is the predicted concentration of copper in interstitial water $(\mu \mathrm{g} / \mathrm{ml}) ; C_{t}$ is the concentration of total copper in the sediment minus the copper in residues $(\mu \mathrm{g} / \mathrm{g})$ according to the sequential extraction procedure (Ge, 1997).

According to the established model, the TS for interstitial water was calculated. We conducted a linear regression analysis between the predicted TS and the biological diversity index (Xu et al., 1994; Zhu et al., 1994). The results (Fig. 4) show that a significant correlation exists between the predicted TS for interstitial water and practical biological diversity index for algae, zooplankton and benthic macroinvertebrates. The coefficient of determinations for the relationships between predicted TS and the diversity index were 0.732 , 0.9719 and 0.9355 for benthos, algae and zooplankton, respectively. From the results, it was concluded that the TS model could be used to predict the ecological effect of heavy metals in sediment on aquatic ecosystems.
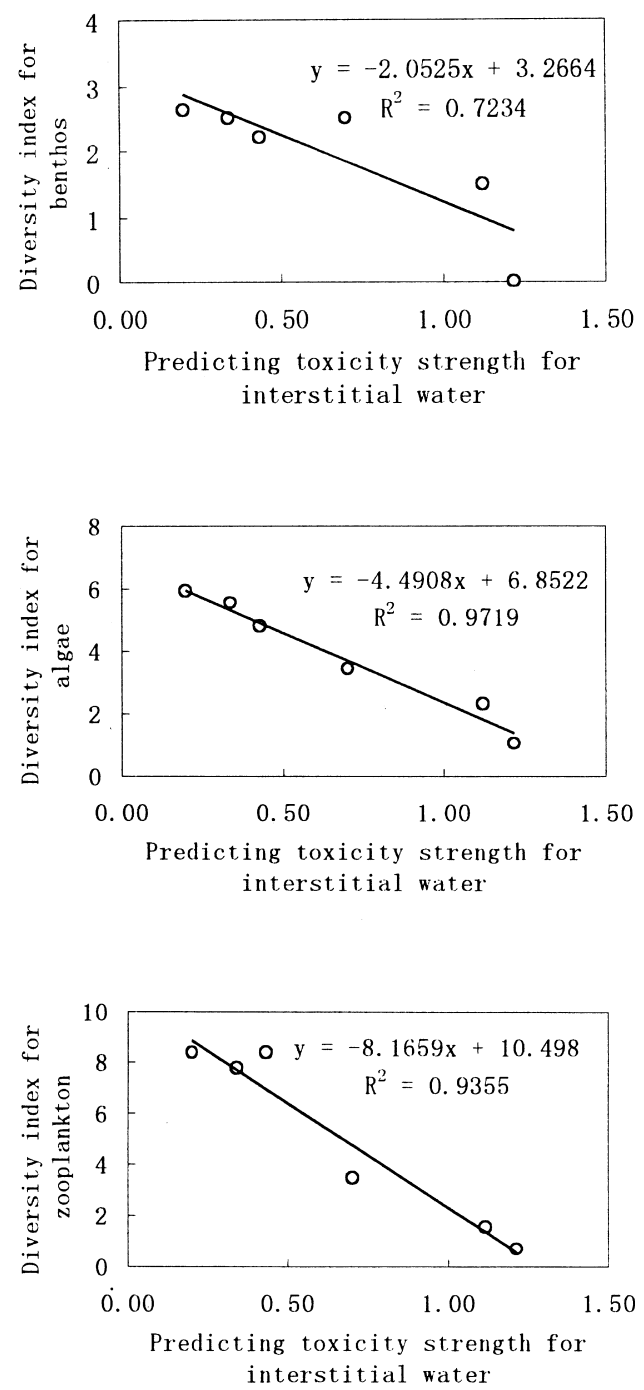

Fig. 4. The linear regression analyses between predicted toxicity strength and biological diversity index. 


\section{Discussion and conclusion}

In contrast to previous models, the predictive model presented emphasizes the link between the physical and chemical processes of heavy metals in rivers and biological effects. The integrated ecological model considers the transport, distribution and speciation of heavy metals as well as metal toxicity to aquatic biota and the effect of environmental variables on metal toxicity. Based on the concept of TS, the suggested predictive model of ecological effect, reflects the relationship between the pollution of heavy metals and their toxicity, and can be used to predict the effect of heavy metals on aquatic ecosystem.

Based on the data obtained from research in the CERP project, the ecological impact of heavy metals on the aquatic ecosystem of the Le An River, polluted by heavy metals from a copper mine, was predicted. The results show that the estimated values of TS for surface water were in agreement with the percentage inhibition of fluorescence intensity for the test organism ( $P$. phosphoreum), and that the predicted ecological effect of the polluted sediment was in agreement with the result of biological assessment.

\section{Acknowledgements}

The authors would like to thank the participants in the project, who also provided data for this paper. Special thanks are due to the German $\mathrm{BMBF}$ and the Chinese CAS for providing funding.

\section{References}

Adami G, Aleffi F, Barbieri P, Favretto S, Reisenhofer E. Bivalves and heavy metals in polluted sediments: a chemometric approach. Water Air Soil Pollut 1997;99:615-622.

Allen HE, Hansen DJ. The importance of trace metal speciation to water quality criteria. Water Environ Res 1996; 68:42-54.

Ankley GT, Di Toro DM, Hansen DJ, Berry WJ. Technical basis and proposal for deriving sediment quality criteria for metals. Environ Toxicol Chem 1996;15:2056-2066.

Dai Z, Wang Z. Model for sulfide weathering in pyritic wastestone. J Environ Sci (China) 1992;4(3):29-35.

Di Toro DM, Mahony JD, Hansen DJ, Scott KJ, Hicks MB,
Mayr SM. Toxicity of cadmium in sediments: the role of acid volatile sulfide. Environ Toxicol Chem 1990;9: $1487-1502$.

Di Toro DM, Zarba C, Hansen DJ et al. Thechnical basis for establishing sediment quality criteria for nonionic organic chemicals using equilibrium partitioning. Environ Toxicol Chem 1991;10:1541-1583.

Ge M. The methodology for establishing the relationship between speciation and bioavailability of heavy metals in sediment on ecosystem level. Master Thesis, Research Center for Eco-environmental Sciences, Chinese Academy of Sciences, 1997:109 pp.

Hakanson L. Aquatic contamination and ecological risk: an attempt to a conceptual framework. Water Res 1984;18: $1107-1118$.

Hansen DJ, Berry WJ, Mahony JD et al. Predicting the toxicity of metal-contaminated filed sediments using interstitial concentration of metals and acid-volatile sulfide normalizations. Environ Toxicol Chem 1996;15:2080-2094.

He M, Wang Z, Tang H. Spatial and temporal patterns of acidity and heavy metals in predicting the potential for ecological impact on the Le An River polluted by acid mine drainage. Sci Total Environ 1997;206:67-77.

He M, Wang Z, Tang H. The chemical, toxicological and ecological studies in assessing the heavy metal pollution in Le An river, China. Water Res 1998;32:510-518.

Lin Y, Li Q. Study on the heavy metal speciation modeling in aquatic system of Le An river. J Environ Sci (China) 1992;4:100-108.

Lin Y, Li Q. The present change of heavy metal pollution in Le An river-Poyang Lake. China Environ Sci 1994;5: 110-115.

Lin Y, Li Q, Zhou G, Shi S. Impacts of acid mine drainage on water quality of Le An River. J Environ Sci (China) 1992;4:91-99.

Liu Q. Relationship between speciation and toxicity of heavy metals in aquatic environment. Ph.D. Thesis, Research Center for Eco-environmental Sciences, Chinese Academy of Sciences, 1996.

Muller G, Tang H. Ecological effects of heavy-metal pollution in the Dexing Copper Mine region in Jiang Xi Province, China. Final report of the Co-operative Ecological Research Project (CERP). United Nations Educational, Scientific and Cultural Organization, 1996.

Mulliss RM, Revitt DM, Shutes RBE. A statistical approach for the assessment of the toxic influences on Gammarus pulex (amphipoda) and Asellus aquaticus (isopoda) exposed to urban aquatic discharges. Water Res 1996;30:1237-1243.

Swartz RC, Ditsworth GR, Schults DW, Lamberson JO. Sediment toxicity to a marine infaunal amphipod: cadmium and its interaction with sewage sludge. Mar Environ Res 1985;18:133-153.

Tang H, Wang Z, Liu J, Muller G. Ecological impacts of heavy metal pollution from Dexing Copper Mine to Poyang Lake - recent research progress in CERP-continual phase. China Environ Sci 1994;5:97-101. 
Ulbrich K, Marsula R, Jeltsch F, Hofmann H, Wissel C. Modelling the ecological impact of contaminated river sediments on wetlands. Ecol Model 1997;94:221-230.

Wu F, Xiong B. Process of sewage disposal in Dexing Copper Mine. Jiangxi Copper Eng 1997;54:5-10.

Xu M, Gao Y, Ma M, Wang Z. The relationship between the changes of plankton community structure and the metal pollution in Le An river. China Environ Sci 1994;5:172-176. Zhu J, Ren S, Lin Z, Lin Y. Preliminary study on the benthic macroinvertebrate community relating to the metal pollution in Le An river. China Environ Sci 1994;5:177-181. 